\title{
Penerapan Budaya Keselamatan Pasien Sebagai Upaya Pencegahan Adverse Events (Kejadian Tidak Diinginkan)
}

\author{
Natasia Atania Sitepu \\ natasiaatania2@gmail.com
}

\section{Latar Belakang}

Rumah Sakit adalah institusi pelayanan kesehatan yang menyelenggarakan pelayanan kesehatan perorangan secara paripurna yang menyediakan pelayanan rawat inap, rawat jalan, dan gawat darurat (Kementerian Kesehatan RI, 2009).

Masyarakat yang dilayani oleh rumah sakit kini mulai gemar menuntut dan semakin cerdas dalam menentukan pilihan (Widajat, 2009). Tuntutan-tuntutan masyarakat ini disebabkan oleh ketidakpuasannya terhadap pelayanan yang diberikan oleh rumah sakit akibat meningkatnya kasus-kasus seperti: kesalahan medis (medical error), kecelakaan (medical accident), kejadian nyaris celaka (KNC), atau kejadian tidak diharapkan (KTD) yang terjadi di rumah sakit.

Perawat dalam memberikan asuhan keperawatan kepada pasien harus menerapkan keselamatan pasien. Perawat harus melibatkan kognitif, afektif, dan tindakan yang mengutamakan keselamatan pasien. Perawat dalam memberikan asuhan keperawatan harus dengan penuh kepedulian. Persepsi perawat untuk menjaga keselamatan pasien sangat berperan dalam pencegahan, pengendalian dan peningkatan keselamatan pasien (Choo, Hutchinson \& Bucknall, 2011; Elley et al, 2008). Pemberi layanan kesehatan berkontribusi terhadap terjadinya kesalahan yang mengancam keselamatan pasien, khususnya perawat, pelayanan terlama ( 24 jam secara terus menerus) dan tersering berinteraksi pada pasien berbagai prosedur dan tindakan keperawatan. Hal ini dapat memberikan peluang yang besar untuk terjadi kesalahan dan keselamatan pasien. Selain itu kelelahan pada perawat merupakan faktor yang berkontribusi terjadinya kesalahan (Mattox, 2012). Karakteristik perawat mempengaruhi pekerjaannya sehari-hari dan berpotensi terhadap kesalahan dalam keselamatan pasien (White, 2012).

Keselamatan pasien merupakan sebuah sistem yang memberikan pasien aman selama di rumah sakit dan dapat mencegah terjadinya cedera yang disebabkan akibat kesalahan melaksanakan tindakan atau tidak mengambil tindakan yang seharusnya diambil. Keselamatan 
pasien adalah Sistem mengurangi risiko bahaya yang tidak perlu berkaitan dengan pelayanan kesehatan minimum sesuai standar pasien (WHO, 2013). Keselamatan pasien adalah pemberian pelayanan kepada pasien lebih aman selama dalam proses perawatan di rumah sakit (PMK RI, 2017).

Fokus terhadap Keselamatan Pasien ini didorong oleh masih tingginya angka Kejadian Tidak Diharapkan (KTD)/Adverse Event (AE) di rumah sakit. Data menunjukkan bahwa angka kejadian KTD yang terjadi di berbagai negara diperkirakan sekitar 3-16\% (WHO, 2005) dan hampir 50\% diantaranya adalah kejadian yang dapat dicegah (Cahyono, 2008, Yahya, 2011).

KTD selain berdampak pada peningkatan biaya pelayanan kesehatan dapat pula membawa rumah sakit ke area blaming. Kondisi tersebut dapat menimbulkan konflik antara dokter/petugas kesehatan lain dengan pasien, dan tidak jarang yang berakhir dengan tuntutan hukum yang sangat merugikan rumah sakit (Depkes RI, 2006). Data KTD di Indonesia masih sulit diperoleh secara lengkap dan akurat, tetapi dapat diasumsikan bahwa angka kejadiannya tidaklah kecil (PERSIKKP-RS, 2011).

Budaya keselamatan merupakan nilai dan keyakinan yang dianut bersama dalam suatu organisasi untuk membuat asuhan pasien yang lebih aman. Pengukuran budaya penting dilakukan untuk menilai bagaimana sikap, persepsi, kompetensi individu dan perilaku orang/kelompok menentukan komitmen dalam meminimalkan insiden di rumah sakit.

Berdasarkan uraian tersebut, penelitian ini difokuskan pada permasalahan budaya kerja, yaitu sejauh mana budaya kerja dapat membentuk budaya keselamatan (yang tercermin dalam 12 dimensi keselamatan pasien) dalam melakukan tugas profesinya masing-masing. Penelitian ini bertujuan untuk memperoleh data tentang penerapan budaya keselamatan pasien untuk mencegah KTD.

\section{Metode}

Metode yang dilakukan dalam penulisan ini adalah metode kepustakaan yaitu dengan melakukan peninjauan, mengumpulkan data-data dan menganalisisnya yang diperoleh dari buku, e-book, jurnal-jurnal terkini ataupun sumber informasi lainnya yang memuat informasi 
pembahasan tentang penerapan budaya keselamatan pasien sebagai upaya pencegahan adverse events (kejadian tidak diinginkan). Pengolahan data dilakukan mulai dari menganalisis isi buku dan jurnal atau sumber informasi lainnya yang berhubungan dengan peran pasien dan keluarga dalam upaya mencegah bahaya dan adverse events (Kejadian Tidak Diharapkan) untuk menjaga keselamatan pasien di rumah sakit.

\section{Hasil}

Keselamatan pasien (patient safety) adalah suatu sistem yang dibuat oleh rumah sakit agar asuhan pasien lebih aman. Sistem tersebut meliputi penilaian risiko, identifikasi dan pengelolaan hal yang berhubungan dengan pasien koma, pelaporan dan analisis accident, kemampuan belajar dari accident dan tindak lanjutnya serta implementasi solusi untuk meminimalkan timbulnya risiko. Tujuan dilakukannya kegiatan Keselamatan pasien di rumah sakit adalah untuk menciptakan budaya keselamatan pasien di rumah sakit, meningkatkan akuntabilitas rumah sakit, menurunkan KTD di rumah sakit, terlaksananya program-program pencegahan sehingga tidak terjadi kejadian tidak diharapkan.

Jenis-jenis kejadian yang memerlukan perhatian, mulai dari "kejadian nyaris cedera (Near miss) sampai dengan "Kejadian Tidak Diharapkan” (Adverse event), Tersedia mekanisme kerja untuk menjmin bahwa semua komponen dari rumah sakit terintregrasi dan berpatisipasi dalam program keselamatan pasien, tersedia prosedure "cepat tanggap" terhadap insiden, termasuk asuhan kepada pasien yang terkena musibah, membatasi risiko pada orang lain dan penyampaian informasi yang benar dan jelas untuk keperluan analisis.

Kejadian tidak diharapkan (KTD)/ adverse event yaitu insiden yang mengakibatkan cedera pada pasien akibat melaksanakan suatu tindakan atau tidak mengambil tindakan yang seharusnya diambil, dan bukan karena penyakit dasarnya atau kondisi pasien. Cedera dapat diakibatkan oleh kesalahan medis atau bukan kesalahan medis.

Elder dan Dovey (2002), membuat sistem klasifikasi kesalahan dalam pelayanan kesehatan yang seharusnya dapat dicegah terkait dengan pelayanan primer dan kesalahan dalam proses, adalah; 1) Klasifikasi kesalahan pada pelayanan primer, meliputi; a) Terkait dengan diagnosis; salah mendiagnosis dan tertunda mendiagnosis. b) Pengobatan; salah obat, salah dosis, tertunda 
administrasi, tanpa administrasi, sedangkan non-obat; ketidaktepatan, terlambat, dihilangkan, komplikasi. c) Pelayanan pencegahan; terlambat, ditiadakan, komplikasi. 2) Klasifikasi kesalahan pada proses; a) Faktor dokter; kesalahan penilaian klinis, kesalahan prosedur keterampilan, b) Faktor perawat; kesalahan komunikasi dan kesalahan prosedur keterampilan, c) Kesalahan komunikasi; dokter-pasien, dokter-dokter atau sistem dan personil pelayanan kesehatan lainnya, d) Faktor administrasi; dokter, farmasi, perawat, terapi fisik, terapi pekerjaan, pengaturan kantor. e) Faktor akhir; pribadi dan masalah keluarga, dokter, perawat dan staf, peraturan perusahaan asuransi, peraturan pemerintah, pembiayaan, fasilitas dan lokasi praktek, dan sistem umum pelayanan kesehatan.

Menurut Yulia dalam penelitiannya (2010), budaya keselamatan adalah kondisi dimana staf memiliki kesadaran yang konstan dan aktif tentang hal yang potensial menimbulkan kesalahan, staf maupun organisasi mampu membicarakan kesalahan, belajar dari kesalahan dan mau memperbaiki kesalahan. Kemudian Ferguson dan Fakelman (dalam Setiowati, 2010) mengemukakan bahwa budaya keselamatan pasien merupakan nilai, kepercayaan yang dianut bersama dengan struktur organisasi dan sistem pengawasan dan pengendalian untuk menghasilkan norma-norma perilaku.

\section{Pembahasan}

Kemungkinan bahwa jutaan pasien seluruh dunia menderita cacat, cedera atau meninggal setiap tahun karena pelayanan kesehatan yang tidak aman. Mengurangi kejadian yang membahayakan bagi pasien merupakan masalah dalam pelayanan kesehatan bagi setiap orang, dan terdapat banyak hal yang harus dipelajari dan dibagi antara negara-negara maju dengan negaranegara berkembang dan negara dalam transisi/konflik tentang masalah keselamatan pasien (World Health Organization, 2009). WHO juga mengingatkan bahwa "keselamatan pasien tidak hanya tentang data statistik tetapi melibatkan kerusakan yang nyata pada kehidupan orang-orang". Oleh karenanya semua strategi dan program keselamatan pasien harus menjadi prioritas dalam pelayanan kesehatan. Pasien, profesional kesehatan dan pembuat kebijakan semua harus bekerja sama untuk membangun sistem kesehatan yang lebih aman. 
Insiden Keselamatan Pasien adalah setiap kejadian atau situasi yang dapat mengakibatkan atau berpotensi mengakibatkan cedera yang seharusnya tidak terjadi. Insiden Keselamatan Pasien ini meliputi Kejadian Tidak Diharapkan (KTD), Kejadian Nyaris Cedera (KNC), Kejadian Potensial Cedera (KPC) dan Kejadian Sentinel.

Keselamatan pasien merupakan hak Pasien. Pasien berhak memeperoleh keamanaan dan keselamatan dirinya selama masa perawatan di Rumah Sakit (Kemenkes,2009). UU No 36/2009 Pasal 53 (3) tentang kesehatan menyatakan bahwa pelaksanaan pelayanan kesehatan harus mendahulukan nyawa pasien. Keselamatan pasien telah menjadi prioritas untuk layanan kesehatan seluruh dunia (Choo, et al. 2010).

Menurut Ananta (2013), kejadian-kejadian yang berkaitan dengan keselamatan pasien semakin marak masuk ke ranah hukum bahkan sampai ke pangadilan. Kenyataan bahwa di rumah sakit terdapat puluhan bahkan ratusan jenis obat, ratusan prosedur, terdapat banyak pasien, banyak profesi yang bekerja serta banyak sistem merupakan potensi yang sangat besar terjadinya kesalahan. Keselamatan pasien merupakan hak pasien yang dijamin dalam UU No. 44 Tahun 2009 tentang Rumah Sakit, untuk itu pihak rumah sakit perlu meminimalkan kesalahan-kesalahan yang mungkin terjadi dalam setiap tindakan yang dilakukan terhadap pasien di rumah sakit.

Keselamatan pasien di Rumah Sakit adalah sistem pelayanan dalam suatu Rumah Sakit yang memberikan asuhan pasien menjadi lebih aman, termasuk di dalamnya mengukur risiko, identifikasi dan pengelolaan risiko terhadap pasien, analisa insiden, kemampuan untuk belajar \& menindaklanjuti insiden serta menerapkan solusi untuk mengurangi risiko. Keselamatan pasien merupakan suatu sistem yang sangat dibutuhkan mengingat saat ini banyak pasien yang dalam penanganannya sangat memprihatikan,dengan adanya sistem ini diharapkan dapat meminimalisir kesalahan dalam penanganan pasien baik pada pasien UGD, rawat inap maupun pada pasien poliklinik.

Rumah sakit seharusnya menyadari arti penting budaya keselamatan pasien karena dengan memahami budaya keselamatan pasien tersebut maka rumah sakit dapat mengidentifikasi program-program yang dapat dilaksanakan sebagai upaya menjamin keselamatan bagi pasien sehingga terbebas dari kejadian yang tidak diharapkan. Waslshe dan Boaden (dalam Setiowati, 2010) menyatakan bahwa kesalahan yang terjadi di rumah sakit kebanyakan disebabkan karena 
kesalahan sistem di rumah sakit yang mengakibatkan rantai-rantai dalam sistem terputus dan bukannya oleh faktor kesalahan dari individu perseorangan saja.

Budaya organisasi berunsurkan nilainilai atau keyakinan (core value) yang berfungsi sebagai perekat organisasi, yang dijadikan dasar dalam membentuk perilaku setiap individu dalam organisasi dalam rangka mencapai visi organisasi. Nilai-nilai yang dimaksud diantaranya adalah melaporkan dan membahas kesalahan/KTD tanpa bersikap menyalahkan, bekerja secara teamwork dan memandang suatu kesalahan dalam kerangka sistem. Jika dikaitkan dengan teori Reiling (2006) dalam Setyawati (2010), budaya keselamatan terdiri atas informed culture, reporting cultur, just culture dan learning culture.

\section{Informed Culture}

Keselamatan pasien sudah diinformasikan ke semua karyawan, arti penting dari ke pasien, ada upaya dari rumah sakit dalam menciptakan keselamatan pasien, adanya kebijakan yang menjadi draf/ rencana strategis tentang keselamatan pasien oleh tatanan manajerial, adanya pelatihan, pengembangan berupa jurnal berdasarkan evience based, informasi tentang kendala dan hambatan dalam menciptakan keselamatan pasien.

Semangat bekerja sama dan saling mendukung untuk terlaksananya program keselamatan pasien telah terbangun. Kondisi ini terjadi karena budaya kerja yang selama ini terbentuk menumbuhkan harapan bahwa program keselamatan pasien yang dicanangkan akan berjalan dengan baik sehingga mampu meminimalkan adanya KTD. Dengan 1 mengadakan berbagai macam kegiatan dan pelatihan-pelatihan baik internal maupun eksternal dalam upaya menurunkan KTD.

\section{Reporting Culture}

Adanya program evaluasi/ sistem pelaporan, adanya upaya dalam peningkatan laporan, hambatan dan kendala dalam pelaporan, adanya mekanisme penghargaan dan sanksi yang jelas terhadap laporan.

Berjalannya proses pelaporan yang baik (non punitif/ tidak menghukum, tepat waktu, dianalisis oleh ahli dan berorientasi pada sistem), hasilnya dapat dimanfaatkan sebagai 
pembelajaran dan berguna untuk menentukan prioritas pemecahan masalah, serta untuk monitoring dan evaluasi keberhasilan dalam penerapan program.

Menurut Cahyono (2008) budaya yang dapat menghambat program keselamatan pasien diantaranya adalah ketakutan terhadap hukuman, cara memandang suatu kesalahan/KTD dimana penyebab KTD dipandang sebagai kesalahan personal dan bukan sistem, respon terhadap kesalahan/ KTD dimana masih terdapat naming (mencari siapa yang salah), blaming (menyalahkan) dan mencari "kambing hitam" pada saat terjadi kesalahan, serta menutupi kejadian KTD, sistem pelaporan yang tidak praktis dan pelaporan yang berujung sanksi. Hasil sebuah penelitian yang dilakukan oleh Tucker dalam Cahyono (2008), para perawat cenderung melakukan penyesuaian diri dengan lingkungan yang tidak aman dan nyaman daripada harus membicarakan ataupun melaporkan suatu kesalahan yang mengakibatkan cedera.

Keterbukaan komunikasi yang dirasakan oleh karyawan masih perlu mendapat perhatian. Hal ini dibuktikan dengan penilaian aspek komunikasi dan umpan balik mengenai insiden keselamatan mendapatkan penilaian respon positif yang paling rendah, Keadaan ini membuktikan bahwa manfaat pelaporan insiden belum sepenuhnya dipahami oleh karyawan, sehingga mereka belum terbiasa melaporkan kejadian kesalahan di unitnya masing-masing.

Menurut Arjaty Daud (2011) masalah yang sering muncul dalam pelaporan insiden diantaranya adalah bahwa laporan masih dipersepsikan sebagai "pekerjaan tambahan" perawat dan laporan sering disembunyikan/under report karena takut disalahkan, terlambat dalam pelaporan dan laporan miskin data karena ada blame culture.

\section{Just Culture}

Staf di rumah sakit terbuka dan memiliki motivasi untuk memberikan informasi terhadap hal yang bisa atau tidak bisa diterima, adanya ketakutan apabila staf melaporkan kejadian kesalahan, kerjasama antar sesama staf.

Herkutanto (2009) menyampaikan bahwa keselamatan pasien sebenarnya tidak terletak dalam diri seseorang, alat/departemen secara individual, tetapi muncul dari interaksi komponenkomponen sebuah sistem dan berada dalam konteks pelayanan yang berkualitas. 
Sebagian karyawan merasakan bahwa kesalahan yang mereka lakukan digunakan untuk menyalahkan mereka, dan bila melaporkan suatu insiden yang utama dibicarakan adalah pelakunya bukan masalahnnya, selain itu karyawan masih merasa khawatir bahwa kesalahan yang mereka buat akan dicatat dalam penilaian kinerja mereka. Karyawan belum merasa bebas membicarakan tentang segala sesuatu yang berdampak negatif pada pasien dan belum merasa bebas menanyakan hal tersebut kepada atasan.

\section{Learning Culture}

Adanya sistem umpan balik terhadap kejadian kesalahan dan pelaporannya, adanya pelatihan di rumah sakit yang menunjang peningkatan SDM.

Karyawan memiliki semangat belajar yang tinggi dan mudah menyerap informasi baru. Menurut Yahya (2006) bahwa nafas dari Patient Safety adalah belajar (learning) dari KTD yang terjadi pada masa lalu dan untuk selanjutnya akan disusun langkah-langkah agar kejadian serupa tidak akan terulang kembali.

Jika pelaporan insiden belum menjadi budaya di seluruh unit, maka proses pembelajaran belum berjalan dengan baik karena budaya pembelajaran dalam keselamatan pasien dimulai dari proses pelaporan insiden dan selanjutnya dianalisis sampai dengan ditemukannya akar masalah yang dapat digunakan sebagai dasar untuk memperbaiki sistem kerja yang berguna dalam menurunkan statistik KTD.

Karyawan telah memahami bahwa penting untuk melaporkan insiden kepada tim keselamatan pasien jika terjadi KTD di unit kerjanya, namun sebagian responden belum melaporkan adanya insiden.

Penerapan keselamatan pasien dapat menurunkan risiko cedera dan membuat asuhan pasien lebih aman. Keselamatan pasien merupakan upaya meminimalkan cereda hingga ke tingkat minimum yang dapat diterima (Panesar, Stevens, Salvilla, \& Sheikh, 2017). Keselamatan pasien adalah sistem yang membuat asuhan pasien lebih aman, meliputi asesmen risiko, identifikasi dan pengelolaan risiko pasien, pelaporan dan analisis insiden, kemampuan belajar dari insiden dan tindak lanjutnya, serta implementasi solusi untuk meminimalkan timbulnya risiko (PMK RI, 2017). Keselamatan pasien membutuhkan tindakan yang strategis dalam penerapannya di rumah sakit. 
Strategi keselamatan pasien dapat diterapkan melalui asuhan keperawatan dalam melakukan setiap tindakan. Tindakan keselamatan pasien ini dilakukan oleh perawat dan seluruh petugas di rumah sakit secara terus menerus, dan dilakukan evaluasi. Insiden dapat diperkecil dengan menerapkan pelaksanaan keselamatan pasien secara terus menerus di rumah sakit (Fujita et al., 2013). Peningkatan penerapan keselamatan pasien wajib dilakukan monitoring dan dapat dilakukan pengukuran. Keselamatan pasien secara keseluruhan terbukti paling berpengaruh terhadap dukungan manajemen rumah sakit untuk pembelajaran organisasi dan perbaikan terusmenerus (Brown, 2016). Monitoring dan evaluasi sangat penting dilakukan untuk mengevaluasi efektifitas keselamatan pasien

Penerapan keselamatan pasien yang kurang efektif dapat terjadi pada identifikasi pasien, kesalahan dalam komunikasi, kesalahan titik operasi, kesalahan obat, infeksi di rumah sakit dan pasien jatuh. Potensi kesalahan biasa terjadi pada identifikasi pasien salah pemberian nama pasient, komunikasi pada saat discharge planning tidak lengkap, dan kurang pengontrolan pasien mengakibatkan pasien jatuh. Kesalahan penerapan keselamatan pasien terbanyak adalah komunikasi yang tidak efektif. Identifikasi risiko dari tahapan layanan dan kondisi pasien harus dilakukan untuk menentukan tindakan pengurangan risiko. Pengendalian risiko merupakan bentuk penerapan keselamatan pasien sesuai standar dapat meningkatkan mutu asuhan keperawatan.

\section{Penutup}

Keselamatan pasien merupakan sebuah sistem yang memberikan pasien aman selama di rumah sakit dan dapat mencegah terjadinya cedera yang disebabkan akibat kesalahan melaksanakan tindakan atau tidak mengambil tindakan yang seharusnya diambil. Kesalahan yang terjadi dalam proses asuhan medis mengakibatkan cedera pada pasien, bisa berupa Near Miss atau Adverse Event (Kejadian Tidak Diharapkan/KTD).

Budaya organisasi berunsurkan nilainilai atau keyakinan (core value) yang berfungsi sebagai perekat organisasi, yang dijadikan dasar dalam membentuk perilaku setiap individu dalam organisasi dalam rangka mencapai visi organisasi. Nilai-nilai yang dimaksud diantaranya adalah melaporkan dan membahas kesalahan/KTD tanpa bersikap menyalahkan, bekerja secara teamwork dan memandang suatu kesalahan dalam kerangka sistem. 
Ciptakan budaya melaporkan KTD dengan cara melakukan sosialisasi secara terus menerus tentang pentingnya melaporkan insiden keselamatan pasien kepada tim KP-RSPR misalnya dengan menyelenggarakan pelatihan khusus tentang pelaporan insiden, mengidentifikasi penyebab rendahnya pelaporan insiden, jika dimungkinkan bisa memberikan hadiah/ reward bagi karyawan yang melaporkan insiden, sedangkan untuk menciptakan keterbukaan berkomunikasi baik antar staf ataupun dengan pihak manajemen perlu dihidupkan kembali kegiatan informal seperti rekreasi bersama ataupun arisan.

\section{Daftar Pustaka}

Bawelle, S. C., Sinolungan, J. S. V., \& Hamel, R. (2013). Hubungan pengetahuan dan sikap perawat dengan pelaksanaaan keselamatan pasien (patient safety) di ruang rawat inap RSUD Liun Kendage Tahuna. Jurnal Keperawatan, 1(1).

Fitriana, Y., \& Pratiwi, K. (2018). Pelaksanaan Patient Safety di Rumah Sakit Umum Daerah dan Rumah Sakit Umum Swasta Bantul Berdasarkan Ketentuan Undang-Undang Nomor 44 Tahun 2009 Tentang Rumah Sakit. Jurnal Kebidanan, 7(1), 28-39.

Hastuti, S. O. (2013). PENERAPAN BUDAYA KESELAMATAN PASIEN SEBAGAI UPAYA PENCEGAHAN KEJADIAN TIDAK DIINGINKAN (KTD) (Doctoral dissertation, Universitas' Aisyiah Yogyakarta).

Kamil, H. (2010). Patient Safety. Idea Nursing Journal, 1(1), 01-08.

Pujilestari, A., Maidin, A., \& Anggraeni, R. (2013). Gambaran Budaya Keselamatan Pasien Oleh Perawat Dalam Melaksanakan Pelayanan Di Instalasi Rawat Inap RSUP Dr. Wahidin Sudirohusodo Tahun 2013. Jurnal Kesehatan Masyarakat, 1-13.

Setyawan, F. E. B., \& Supriyanto, S. (2019). Manajemen rumah sakit. Zifatama Jawara.

Simamora, R. H. (2019). Buku ajar pelaksanaan identifikasi pasien. Uwais Inspirasi Indonesia.

Siregar, R. (2016). Hubungan Perawat dan Pasien: Implementasi Standar Keselamatan Pasien. tora, 2(1), 295-304. 
Susanti, S. S., Anggraini, D. D., Perangin-angin, M. A., Girsang, B. M., Ritonga, I. L., Tahulending, P. S., ... \& Purba, D. H. (2020). Manajemen dan Kepemimpinan dalam Keperawatan. Yayasan Kita Menulis.

Widiasari, W., Handiyani, H., \& Novieastari, E. (2019). Kepuasan Pasien Terhadap Penerapan Keselamatan Pasien di Rumah Sakit. Jurnal Keperawatan Indonesia, 22(1), 43-52.

Yustina, E. W. (2012). Mengenal Hukum Rumah Sakit. CV Keni Media. 